\title{
PORTFOLIO ANALYSIS WITH SECOND ORDER STOCHASTIC DOMINANCE BY THE PERSPECTIVE OF CAPITAL STRUCTURE: AN IMPLEMENTATION ON BIST-100 INDEX
}

DOI: 10.17261/Pressacademia.2017.692

JEFA- V.4-ISS.3-2017(4)-p.245-255

Oktay Tas $^{1}$, Ali Sezin Ozdemir ${ }^{2}$. Kaya Tokmakcioglu ${ }^{3}$

${ }^{1}$ Istanbul Technical University, Macka Campus, Istanbul, Turkey. oktay.tas@itu.edu.tr

${ }^{2}$ Istanbul Technical University, Macka Campus, Istanbul, Turkey. ozdemiralisezin@gmail.com

${ }^{3}$ Istanbul Technical University, Macka Campus, Istanbul, Turkey. tokmakcioglu@itu.edu.tr

To cite this document

Tas, O. Ozdemir, A.S. and Tokmakcioglu, K., (2017). Portfolio analysis with second order stochastic dominance: an implementation on BIST100 index by the perspective of capital structure,. Journal of Economics, Finance and Accounting (JEFA), V.4, Iss.3, p.245-255.

Permemant link to this document: http://doi.org/10.17261/Pressacademia.2017.692

Copyright: Published by PressAcademia and limited licenced re-use rights only.

\begin{abstract}
Purpose- The aim of this paper is to observe whether generating a portfolio having return more than index by investigating the return performance of index's stocks and capital structure of firms in index in a certain period. The second aim of this paper is to provide portfolio diversification by using the method of this study. In this paper, firms and stocks on BIST-100 index are referenced for empirical study. Method- Stocks are chosen from BIST-100 index with regard to certain capital structure of firms in stocks, and second orderly stochastic dominance test is implemented on these stocks. Dominant stocks are defined to generate a portfolio after stochastic test and this portfolio's return performance is compared to the index'-s return.

Findings- The portfolio, whose stocks are filtered by a certain capital structure and then chosen by second orderly stochastic dominance test, has return performance better than index's return.

Conclusion- This paper is indicating that second orderly stochastic dominance method and capital structure is an important investigation to generate a portfolio having higher returns more than index's.
\end{abstract}

Keywords: Capital structure, second order stochastic dominance, portfolio analysis, D/E ratio, returns over index JEL Codes: G11, C02

\section{SERMAYE YAPISI BAKIŞ AÇISIYLA İKINCI DERECEDEN STOKASTIK BASKINLIK YÖNTEMI ILE PORTFÖY ANALIZI: BIST-100 ENDEKSI ÜZERINDE BİR UYGULAMA}

\section{ÖZET}

Amaç- Bu çalışmanın amacı, bir endekse ait hisselerin, belirli bir dönemdeki getiri performansına ve sermaye yapısına bakarak, hemen devamındaki diğer bir dönem için, getirisi endeksin getirisinden yüksek bir portföy oluşturmanın mümkün olup olmadığını gözlemlemektir. Bu çalışmanın ikinci amacı ise bu yol ile portföy çeşitlendirmesinin sağlanmasıdır. Bu çalışmada, hisse ve sermaye yapısı incelenmesi için BIST-100 endeksindeki şirketler referans alınmıştır.

Yöntem- BIST-100 endeksi hisseleri arasından belirli bir sermaye yapısına uygun firmaların hisseleri seçilmiş ve bu hisseler ikinci dereceden stokastik baskınlık testine tabi tutulmuştur. Bu testin sonucunda seçilen hisseler ile oluşturulan portföyün getirisi ile endeksin getirisi karşılaştırılmıştır.

Bulgular- Sermaye yapısı filtresinden geçen ve ikinci dereceden stokastik baskınlık yöntemi ile tespit edilen hisseler ile oluşturulan portföyün getirisi, endeksin getirisinden fazla olmuştur.

Sonuç- Bu çalışma ikinci dereceden stokastik baskınlık yönteminin ve sermaye yapısı incelemesinin, getirisi yüksek bir portföy oluşturmada önemli bir etkisi olduğunu göstermektedir.

Anahtar Kelimeler: Sermaye yapısı, İkinci dereceden stokastik baskınlık, Portföy analizi, Borç/Özsermaye oranı, Endeks üstü getiriler JEL Kodları: G11, C02 


\section{GiRiş}

Firma sermaye yapısı ve firma değeri arasındaki ilişki hem teorik hem de deneysel çalışmaların konusu olmuştur. Firmalarda optimal bir sermaye yapısı olup olmadığı ve borç kullanım oranının firma değeri ile ilişkili olup olmadığı araştırma konularının odak noktalarından biridir.

\subsection{Sermaye Yapısı Hakkında İncelemeler}

Modigliani ve Miller (1958) teoride şirket borç oranının firmanın değerini etki etmediğini gösterseler de; vergiden düşülebilir faiz ödemesinin olduğu gerçek dünyada, firma değeri ve sermaye yapısı arasında pozitif bir ilişki olduğunu da belirttiler. Baxter (1967) ve Stiglitz (1972) ilerleyen yıllarda iflas maliyeti, vekalet maliyeti, vergi avantajı gibi konuları optimum sermaye yapısının incelemesine dahil ettiler.

Konu ilerleyen yıllarda (Masulis, 1983) daha ayrıntılı incelenmiştir. Borçlu firmaların borç oranlarının, endüstri ortalamasına yaklaştığı durumlardaki pazar tepkilerinin; borçlu firmaların endüstrinin ortalamasından uzaklaştığı durumlara göre daha pozitif olduğu durumu tartışılmıştır.

Bu çalışmasında Masulis'in belirttiği pazar etkisi durumu test edilmiştir. 183 firmanın borçlanma duyuruları (fon oluşturma, borçlanarak kaynak yaratma gibi) göz önüne alınarak; firmaların sermaye oranları (kaldıraç oranları) endüstrinin altında ve endüstrinin üstünde olarak iki grupta sınıflandırılmıştır. Value Line ve COMPUSTAT gibi veri kaynakları kullanılarak, endüstri oranları alınırken, firmaların özkaynaklarının hem defter hem de pazar değeri verilerine de ulaşılmıştır. Ardından firmanın hisse değerlerine bir etkisi olup olmadığı test edilmiştir. Sonuç olarak her iki grup için de borçlanma duyurularının pazara etkisinde kayda değer bir etki görülmemiştir. Ayrıca firmaların borçlanma oranı ile endüstrinin borçlanma oranı arasında önemli bir ilişki görülmemiştir. Kayda değer olmayan bu ilişki, her bir firmanın beklenen büyüme oranları için kontrol edildiğinde de devam etmektedir. Bu çalışma; Masulis'in "Bir firma, endüstrinin borç oranı ortalamasına yaklaşırsa, değeri artabilir." argümanını desteklemez.

Tekil endeks market modeli (Single index market model) borçlanma duyurularının pazar reaksiyonunu hesaplamak için kullanılmıştır. Firmalar, Value Line endüstriyel sınıflandırması yapılarak ve Uzun dönem borç / Net Değer (LTD/ Net Worth) formülü kullanılarak, endüstri ortalamasının altında kalan firmalar düşük borçlu firmalar; ortalamanın üstünde kalan firmalar ise yüksek borçlu firmalar olarak iki gruba ayrılmıştır. COMPUSTAT sınıflandırılmasında ise Toplam Borç / Özkaynak'ın Pazar Değeri ( TD/MVE) formulasyonu kullanılarak firmalar yine düşük borçlu firmalar ve yüksek borçlu firmalar olarak endüstri ortalamalarına göre sınıflandırılmışlardır.

i) Bu sonuçlara göre örneklemeler iki gruba ayrılmadan yapıldığında, borç duyurusu yapıldıktan sonra 2 ila 90 gün arasında bir değer kaybı gözükmektedir.

ii) İki gruba ayrılarak test edildiğinde yüksek borçlu firmaların pazar reaksiyonunun negatif yönde olduğu tespit edilmiştir. Düşük borçlu firmalar ile yüksek borçlu firmalar arasında borçlanma duyurusundan 1 gün önceki farkları haricindeki diğer farklar kayda değer değildir. -1 gününde yüksek borçlu firma düşük borçlu firmaya göre borçlanmasına rağmen \% 0,53 daha fazla değer kazandırmıştır. Bu durum da " yüksek borçlu firmalar borcunu azaltarak değerini arttırır" beklentimizle çelişmektedir. Genel olarak farkların kayda değer olmaması, " hisse senedi piyasası, endüstriyel borçlanma oranlarını, borçlanma duyurularına cevap vermede, belirleyici bir faktör olarak kullanmaz." çıkarımında bulunmamızı sağlar.

iii) Düşük büyümeli-yüksek borçlu firmalar Jensen'e (1976) göre en favori pazar reaksiyonunu alırlar. Çünkü fazladan borçlanma yönetimi kontrol etme durumunu sağlar. Tam tersimi düşündüğümüzde düşük borçlu-yüksek büyüme oranlı firmalar ek borçlanma yapmamalıdırlar. Çünkü nakit fazlası, şirkette ikramiye olarak dağıtılacaktır. Value Line datasında bu durum -5 ile 5 günleri arasında gözlemlenmiştir. Yüksek boru firma borçlanmaya karşı pozitif etki vermiştir. Bu durum Jensen'in yüksek borçlu-düşük büyümeli firmanın fazladan borçlanması yönetimsel kontrolü arttırdığı yönündeki önerisini ıspatlar niteliktedir.

Sonuç olarak; yapılan bu çalışma Masulis ve DeAngelo'nun (1980) "firmalar borç oranlarını değiştirerek firma değerini arttırabilir veya azaltabilir" ve "firmalar optimum bir borç oranı ararlar." tezlerini destekleyecek bir argümana ulaşamamıştır. Hem defter değeri hem de pazar değeri verileri kullanmasına rağmen sonuç değişmemiştir. Temel sonuç ise firmanın borç seviyesi ve endüstri arasındaki ilişki,pazarın kayda değer olarak kabul ettiği bir değişiklik etkeni değildir. Ancak yüksek borçlu firmaların genel olarak borçlanma duyuruları negatif bir etki yaratmıştır. Önceki araştırmalar,sermaye yapısı ve endüstriyel durum arasında bir ilişki olduğunu göstermelerine rağmen; bu çalışma bir firmanın borçlanma oranı ile endüstrinin borçlanma orasındaki ilişkinin kayda değer ve önemli olmadığını ıspatlamaktadır.

Sermaye yapısı, sermaye yapısını hangi faktörlerin etkilediği İslami finansa dahil olan firmaların da en temel araştırma konularından biri olmuştur (Erdamar E., 2015). 1990'lardan beri süregelen araştırmalar sonucunda, İslami finansın dünyada yayılmaya başlamasıyla birlikte İslami finans araştırmaları sermaye yapısı bakımından artmıştır. İslami firmaların, banka kredileri, sattıkları ürün çeşitliliği ve aktif oldukları iş alanlarında bir takım sınırlandırmalar mevcuttur. Bu durumda İslami 
firmaları diğer firmalardan ayıran bir sermaye yapısı olması gerekmektedir. Bu çalışmada şirketler özelinde ve ülkeler özelinde borçlanma etkenleri, dünyanın en eski İslami endekslerinden biri olan Dow Jones İslami Endeks'inden detaylandırılarak araştırma yapılmıştır. İslami firmalardan beklenen düşük borç oranına sahip olmasıdır. Erdamar'ın (2015) çalışmasındaki ilk analiz isslami firmalar ile normal firmaların sermaye yapısını ve borç oranlarını Dow Jones'daki 40 farklı ülkeden şirketin verilerini de konsolide ederek incelemesidir.

Çalışmanın sonucu göstermiştir ki gelişmiş bankacılık ve sermaye sektörüne sahip olan ülkelerde İslami firmaların borç oranları normal firmalardan farklı değildir. Ayrıca İslami firmalar, bu sektörlerin gelişmiş olduğu ülkelerdeki finansal enstrümanları kullanmaktalar. 2009 krizinden sonra düşük borç oranına yönelim olsa bile, firmaların sermaye yapısı tercihleri üzerinde bir etkiye sahip olmamıştır.

Erdamar'ın çalışması (2015) hakkındaki bazı sonuçlar ve tespitler aşağıdaki gibidir;

i) Gelişmekte olan ülkelerin ortalama borç oranı ile gelişmiş ülkelerin borç oranı birbirine yakındır ancak, gelişmiş ülkelerin bu oranı biraz daha düşüktür.

ii) Ortalama kar oranı gelişmekte olan ülkelerde, gelişmiş ülkelere göre biraz daha fazladır. Gelişmekte olan ülkelerin firmalarındaki kar oranı, gelişmiş ülkelere nazaran daha stabildir.

iii) Envanterin toplam varlığa oranı gelişmekte olan ülkelerdeki firmalarda, gelişmiş ülkelerdeki firmalara göre daha fazladır. Ancak sabit kıymetlerin toplam varlığa oranı gelişmiş ülkelerdeki firmalarda, gelişmekte olan ülkelerdeki firmalara göre daha azdir.

iv) Likidite oranları gelişmiş ülkeler ile gelişmekte olan ülkeler arasında benzerdir.

v) Boyut bakımında kabul edilen satış boyutları iki gruplanmış ülkeler arasında birbine benzerdir.

vi) $\mathrm{P} / \mathrm{B}$ oranı ve iflas eşiğine olan yol oranı (distance from bankruptcy) gelişmekte ve gelişmiş ülkeler arasında birbirine benzerdir.

vii) Hisse Senedi Piyasası toplamı (büyüklügü) gelişmiş ülkelerde beklendiği gibi daha büyüktür. Öte yandan, enflasyon oranı ve gayri safi millli hasıla büyüme oranı gelişmiş ülkelerde daha düşüktür. Volatilite gelişmekte olan ülkelerde daha azdır.

viii) Bağımsız değişkenler gelişmekte olan ülkelerde daha az kırılgan yapıya sahiptir.Bu durum gelişmekte olan ülkelerdeki firmaların finansal Shari'ah Kanunlarına daha fazla uyduğunu göstermektedir. İslami endekslerdeki firmalara göre, gelişmiş ülkelerdeki firmalarda daha fazla çeşitlilik ve farkılıı vardır.

Hausman Taylor Analizine göre;

i) Kar edilebilirlik katsayısı, satış oranları, P/B oranı gibi firma özelindeki karakteristikler İslami finansın sermaye yapısını belirleyen temel faktörlerdir. Bu özellikler firmaların gelişmiş ülkelerde veya gelişmekte olan ülkelerde olmasından bağımsızdır.

ii) Gelişmekte olan ülkeler için, firma karakteristikleri arasından olan toplam borç oranını belirleyen faktörler kar edilebilirlik ve bir önceki yılın borç oranıdır. Bir önceki yııın borç oranı yükseldikçe karlılık düşer.

Sonuç olarak Erdamar'ın bu çalışmasında; firma-ülke karakteristik finansal özelliklerin, Dow Jones Islamıc Market endeksinde sınıflandırımış olan firmaların kaldıraç oranları üzerindeki etkilerini analiz edilmiştir. Sınıflandırılmış İslami firmalar Sharia kurallarına uyar. Ancak uydukları bu sermaye yapısı gerçekten diğerlerinden farklı mıdır? Bu soruyu literatürde ilk ortaya çıkaran bu çalışma olmuştur.

i) Profitability (Kar edebilirlik), satışlar, likidite gibi özellikler İslami firmalarda diğerlerinden çok farklı değildir.

ii) Bu analiz gösteriyor ki kaldıraçları belirleyen ana faktörler, gelişmiş ve gelişmekte olan ülkelerde sabit kalsa bile, mixed bir analiz yapmak çok öncü sonuçlar doğurmaz. Bu sebeple bu alanda çalışma yapmak isteyen bir kişi ekonomik verileri de hesaba katmak zorundadır.

iii) Brezilya, Meksika, Hindistan gibi gelişmekte olan ülkelerin firmaları yüksek kaldıraç oranlarına sahipken; Litvanyalı firmalarda bu oranlar düşüktür. (Leverage Ratios)

iv) Islami kuralları uygulayan firmaların borç oranları Müslüman olmayan ülkelerde daha fazladır. Müslüman bir ülkede faaliyet gösteren firma sermaye yapısını ne negatif ne de pozitif bir şekilde etkileyememiştir. Bu durum ilginçtir.

v) İsviçre, Almanya, Fransa, İsveç, İngiltere firmaları daha yüksek kaldıraç oranlarına sahipken; Uzakdoğu ülkelerinde bu oran daha düşüktür. 
Erdamar'a göre (2015), bir diğer çalışma, endüstri-seviyesindeki faktörler, ülke içindeki yozlaşma seviyesi gibi bilgileri de firma kaldıraç oranları belirleyenleri arasından inceleyebilir. İslami olmayan firmaların sermaye yapısı ile onları İslami firmalarla karşılaştıran bir çalışma da ilginç sonuçlar gösterebilir.

Bu çalışmada 10 gelişmekte olan ülkelerdeki firmalarının sermaye yapısı kararları incelenmiş olup, bu kararların gelişmiş ülkelerdeki aynı değişkenlerden etkilendiğine dair kanıtlar elde edilmiştir. Sermaye yapısına ait olan bilgilerimiz gelişmiş ülkelerdeki kurumsal benzerlikler taşıyan firmalar üzerine yapılan araştırmalardan gelmektedir. Bu çalışmada ise gelişmekte olan ülkelerdeki farklı kurumsal yapıya sahip firmalar arasındaki sermaye tercihleri araştırılmıştır.

Booth, Aivazian, Demirguç ve Maksimov'un Gelişmekte Olan Ülkelerin Sermaye Yapısı (2001) adlı makalesinde; firmaların sermaye yapısı kararlarının gelişmiş ve gelişmekte olan ülkelerdeki benzerliği; sermaye yapılarındaki kesişimsel çeşitliliği etkileyen bu faktörlerin benzerliği; geleneksel sermaye yapısı tahminlerinin (vergi oranı, iş riski gibi) geliştirilebilirliği konularına bakılmıştır.

Data kaynakları ve makro finansal bilgilerin paylaşıldığı ilk bölümde; toplam borç oranı Brezilya'da \% 30,3 iken Kuzey Kore'de $\% 73,4$ 'tür. Brezilya, Meksika, Malezya ve Zimbabwe düşük borç oranlı grubu oluştururken; yüksek borç oranlı grup Hindistan, Güney Kore, Pakistan'dan oluşmaktadır. Orta düzeyli borç oranına sahip grupta ise Tayland, Ürdün ve Türkiye bulunmaktadır.Defter ve market değerine baktı̆̆ımızda benzer özellikler göstermektedirler. Zimbabwe ve Ürdün gibi ülkelerde market değeri durumuna göre bazen yüksek borç oranlı ülkeler grubuna girmektedir.

Makroekonomik verilere göre Ürdün, Brezilya ve Meksika göreceli olarak düşük reel ekonomik büyüme oranlarına sahiptirler. Taylan ve Güney Kore aynı periyotta yüksek büyüme oranına sahip ülke olarak göze çarpmaktadır. Ülkelerin genelinde yüksek enflasyon oranı görülmektedir. Brezilya ve Meksika ise hiperenflasyon ortamına sahip olmuştur.

$A B D$ ve Avrupa ülkelerindeki sermaye yapısı değişkenleri, kurumsal faktörlerdeki farklılıklara rağmen gelişmekte olan ülkelerle de ilişkilidir. Bu faktörleri bilmek bir firmanın finansal yapısını daha iyi tahmin etmemizi sağlamaktadır. Hem ülkelerdeki ve hem de datalardaki sonuçlara baktığımızda ne kadar daha fazla karedilebilirlik, daha düşük borç oranına sebep olur. Bu durumda ilgili firma için ne kadar borç oranı belirlendiği gözardı edilebilir. Karlı firmaların daha az dış finansal kaynaklar kullandığı durumuyla da açıklanabilir (Donaldson ve Higgins,1963). Öte yandan vergi avantajından yararlanmak isteyen firmaların borç kaynaklarına yönelmesi durumu ile Higgins ve Donaldson'un bulmuş olduğu sonuçla çelişir. Yüksek büyüme oranlı ve yüksek market-to-book oranına sahip şirketler, yüksek agency (vekalet) maliyetinden dolayı düşük borç oranını tercih edebilirler. Ancak borç oranına negatif etki eden durumlardan biri olan ortalama-vergi-oranı ; yüksek karlılı̆ı açıklamaktadır. Varlıkların borçlanmada oynadığı rol de önemlidir. Toplam ve uzun dönem borçlanma oranlarını etkilemektedir. Daha somut varlıklara sahip şirketlerde, daha yüksek uzun dönem borç oranı ancak daha düşük toplam borç oranı gözükmektedir. Bu durum uzun dönemli borç oranının kısa dönemli borç oranına göre tercih edildiğinin göstergesidir.

Booth, Aivazian, Demirguç ve Maksimov'un bu çalışmasına göre (2001) genel olarak, gelişmekte olan ülkelerdeki borç oranlarının; gelişmiş ülkelerdeki aynı değişken ve aynı yollardan etkilendiği bu çalışmada görülmüştür. Böyle olmakla birlikte, enfasyon oranı, GSMH büyüme oranı, sermaye piyasasının bu oranları etkilemesinde sistematik farklılıklar mevcuttur.

\subsection{Portföy Çeşitlendirmesi Konusundaki İncelemeler}

Portföy çeşitlendirmesi konularında, farklı endekslerin birliktelik hareketlerinden de yararlanılanmaktadır. Mazouz, Mohamed ve Saadouni'nin (2016) tek değişkenli analizinde, DJMWI (Dow Jones Islamic Market World Index) endeksine yeni dahil olan ve yeni silinen hisselerin, endeks ile birlikteliğine bakılmıştır. Endekse dahil olan hissenin, endeksin hareketi ile birlikteliği olduğu, silinen hissenin ise bu birlikteliği kaybettiği sonucuna varılmıştır. Bu bilgileri portföy çeşitlendirilmesine kullanmak üzere atıfta bulunulmuştur. Bu çalışmalara paralel olarak Alaoui, Dewandaru, Rosly ve Masih'in (2014) ampirik çalışmasında kesikli dalgacık dönüşümü tekniği kullanılmış ve Islamic Dubai Financial Market ile GCC, ASEAN endeksleri birliktelikleri karşılaştııılmış ve lokasyon olarak birbirine yakın olmaları sebebiyle, endeksler arasında yüksek korelasyon bulunmuştur. Yazarlar, yine portföy çeşitlendirmesi için bu birliktelikler doğrultusunda da atıfta bulunmuşlardır. Bu çalışmada ise portföy çeşitlendirmesinde kullanılan bu yöntemlerden biri olan stokastik baskınlık yöntemi kullanılmıştır.

\section{3 İkinci Dereceden Stokastik Baskınlık Testi Uygulaması}

Günümüz dünyasında finansal yatırım araçlarından pozitif getiriler elde etmek için geliştirilen portföy analizi yöntemleri, olumsuz ekonomik koşullar ve risklerin yükselmesi sebebiyle, bazen negatif getirilere sebep olmaktadır. Ayrıca yalnızca endeksi referans alarak veya endeksi referans alan finansal araçlara yapılan yatırımlar, endeksin ilgili ülkedeki ekonomik etkilerden olumsuz etkilenmesi sebebiyle negatif getirilere de sebep olmaktadır. Bu negatif etkilerden korunmak için geliştirilen ve varyans maksimizasyonu yönteminden daha iyi sonuçlar veren stokastik baskınlık testleri günümüzde yatırımcı şirketler tarafından kullanılmaya başlaşmış olup, konuyla ilgili Ar-Ge çalışmaları da yapılmaktadır. (Güran, Taş, 2014). Bu çalışmada belirli bir sermaye yapısı referans alınarak seçilen BIST100 içindeki bazı firmaların hisse senetlerinin günlük hareketleri, ikinci dereceden stokastik baskınlık yöntemi ile karşılaştııılmış ve bu firmalardan oluşturulan portföyler, endeks 
ile karşılaştırımıştır. Bu yolla sermaye yapısına da atıfta bulunulmuştur. Bu çalışmanın hipotezi ve alternatif hipotezi aşağıdaki gibidir.

$\mathbf{H}_{0}$ : \%0-50 toplam borç/özsermaye oranına sahip olan BIST100 içinden seçilen firmaların hisse senetlerine, 2.dereceden stokastik baskınlık testi uygulanmasıyla oluşturulan bir portföyün belirli bir dönem sonrasındaki getirisi; aynı döneme ait olan BIST100'ün kendi getirisinden fazladır.

$\mathbf{H}_{\mathbf{a}}$ : \%0-50 toplam borç/özsermaye oranına sahip olan BIST100 içinden seçilen firmaların hisse senetlerine, 2.dereceden stokastik baskınlık testi uygulanmasıyla oluşturulan bir portföyün belirli bir dönem sonrasındaki getirisi; aynı döneme ait olan BIST100'ün kendi getirisinden azdır.

Bu çalışmada stokastik baskınlık ve borç oranı birlikte düşünülmüştür. İkisinin ortak kullanımı sonucu oluşturulan bir portföyün getirisinin, BIST100'ün getirisinden daha fazla olacağı öngörüsüyle ilerlenmiştir. 2.bölümde stokastik baskınlık yönteminin teorik detayları anlatılmış ve baskınlık testi değerlendirmelerinin nasıl yapılması gerektiği hakkında bir örnek anlatılmıştır. Sermaye yapısı ile ilgili seçim yöntemleri 3.bölümde detaylandııılmıştır. Yapılacak olan hisse senedi seçimlerinin nasıl yapıldığı ve stokastik baskınlık testinin nasıl uygulandığı adım adım anlatılmıştır. 4.bölümde bu testlerin sonucunda ortaya çıkan portföyün performansı, endeksin getiri performansı ile karşılaştırılmış ve bulgular yorumlanmıştır. Son bölümde ise sermaye yapısı ve portföy performansı arasındaki ilişkiler değerlendirilmiştir.

\section{LITERATÜR TARAMASI}

\subsection{Stokastik Baskınlık}

Stokastik baskınlık, belirsizlik koşullarında karar verme teorileri bakımından temel bir kavramdır. Herhangi bir hisse senedi veya loto getiri ihtimalleri baz alınarak, bir hisse senedinin diğer hisse senedine oranla stokastik olarak baskınlık durumu incelenir. Birinci derece stokastik baskınlık ve ikinci derece stokastik baskınlık olarak yapılan çalışmalar riskten kaçınan yatırımcılar için optimize bir portföy sağlar (Güran, Taş, 2014). Birinci ve ikinci dereceden stokastik baskınlık yöntemleri aşağıdaki gibi açıklanmıştır.

i) Birinci Dereceden Stokastik Baskınlık (First-Order Stochastically Dominance): $Y, X^{\prime}$ e göre birinci dereceden stokastik baskınlığa sahiptir, eğer;

$$
F(t) \leq G(t)
$$

F ve G, sırasıyla Y ve $X^{\prime}$ in kümülatif olasılık dağııımlarını temsil etmektedir.

ii) İkinci Dereceden Stokastik Baskınlık (Second Order Stochastically Dominance): Y, X'e göre ikinci dereceden stokastik baskınlığa sahiptir, eğer;

$$
\int_{-\infty}^{x} F(t) d t \leq \int_{-\infty}^{x} G(t) d t
$$

F ve G, sırasıyla Y ve X'in kümülatif olasılık dağılımlarını temsil etmektedir.

\section{2 İkinci Derece Stokastik Baskınlık (SSD) Kullanarak Verimlilik Analizi}

Portföy analizi için en verimli SSD seti, hiçbir hisse senedi tarafından domine edilmeyen hisseler ile oluşturulan bir portföydür. SSD verimliliği konusunda, Yitzhaki ve Mayshar verimsiz portföylerin geliştirilmesi yönünde çalışmalar yapmıştır (2001). Güran (2013) SSD verimliliği testini BIST'e uygulamıştır. (Güran, Taş, 2014)

SSD, N sayısında varlığı olan bir portföyün tüm hisselerini birbiri ile karşılaştırır. Toplam karşılaştırma sayısı aşağıdaki gibidir:

$$
\mathrm{N}=\mathrm{N} ! /\left[2^{*}(\mathrm{~N}-2) !\right]
$$

Örneğin, aşağıdaki örnek tabloda ARCLK, ASYAB ve DOHOL hisselerinin her bir günlük getirileri (toplam 135 gün) küçükten büyüğe doğru sanki bir olasılık listesine aitmiş gibi sıralanmıştır. Günlük yüzdelerin her biri birer olasılıkmış gibi düşünülür. Turuncu kolon bunu gösterir. Sarı kolonda ise bu olasılıklar kümülatif olarak toplanır. Ardından firmaları karşılaştırmak için bu kümülatif toplamlar da firma-firma karşılaştırılır. Bu karşılaştırılmalar getiri farkları ile çarpııır ve her bir satırda tekrar kümülatif olarak toplanır. Her bir kümülatif toplamın işareti pozitif veya negatifse, bu durum baskınlık ile ilgili bilgi verir. Örneğin pembe kolonda ARCLK hissesi, ASYAB ve DOHOL hisselerine karşı baskın gelmiştir. ASYAB ve DOHOL arasında ikinci dereceden baskınlık ilişkisi bulunamıştır. Çünkü kümülatif toplamlar hem pozitif hem negatif değerlere sahiptir. (Tablo satırsal olarak kısaltılmıştır. Çünkü toplam satır sayısı 350’yi geçmiştir.) 
Tablo 1: ARCLK, ASYAB ve DOHOL Hisselerinin İkinci Dereceden Stokastik Baskınlık Testi Örneği

\begin{tabular}{|c|c|c|c|c|c|c|c|c|c|c|c|c|c|}
\hline $\begin{array}{c}\text { Return } \\
\text { Difference }\end{array}$ & Return & ARCLK & ASYAB & DOHOL & CUM(AR) & CUM(AS) & CUM(DOHC & \begin{tabular}{|c} 
RD*[Cum \\
(ARC)- \\
Cum(ASY) \\
]
\end{tabular} & $\begin{array}{c}\text { SUM } \\
\text { RD*[Cum(ARCELIK)- } \\
\text { Cum(ASYA)] }\end{array}$ & \begin{tabular}{|c|} 
RD*[Cum \\
(ARCELIK) \\
Cum(DOH \\
C)]
\end{tabular} & $\begin{array}{c}\text { SUM } \\
\text { RD*[Cum(ARCELIK)- } \\
\text { Cum(ADOHC)] }\end{array}$ & $\begin{array}{c}\text { RD*[Cu } \\
\text { m(ASYA) } \\
\text { Cum(DO } \\
H C)] \\
\end{array}$ & $\begin{array}{c}\text { SUM RD*[Cum(ASYA)- } \\
\text { Cum(DOHC)] }\end{array}$ \\
\hline 0,08 & $-0,29$ & - & - & 0,007 & - & - & 0,007 & - & - & 0,001 & 0,001 & $-0,001$ & 0,001 \\
\hline 0,03 & $-0,21$ & - & - & 0,007 & - & - & 0,015 & - & 0,000 & $-0,000$ & 0,002 & $-0,000$ & 0,001 \\
\hline 0,05 & $-0,18$ & - & 0,007 & - & - & 0,007 & 0,015 & $-0,000$ & 0,000 & 0,001 & 0,002 & $-0,000$ & 0,001 \\
\hline 0,02 & 0,14 & - & - & 0,007 & 1,000 & 1,000 & 0,970 & - & 0,009 & 0,001 & 0,005 & 0,001 & 0,004 \\
\hline 0,02 & 0,16 & - & - & 0,007 & 1,000 & 1,000 & 0,978 & - & 0,009 & 0,000 & 0,005 & 0,000 & 0,004 \\
\hline 0,01 & 0,18 & - & - & 0,007 & 1,000 & 1,000 & 0,985 & - & 0,009 & 0,000 & 0,004 & 0,000 & 0,005 \\
\hline
\end{tabular}

\begin{tabular}{|c|c|c|}
\hline ALL NEGATIVE & ALL NEGATIVE & DIFFERENT VALUES $(+,-)$ \\
\hline$\sum[F($ Arcelik)-F(Asya) $] \leq 0$ & $\sum[\mathrm{F}($ Arcelik) $-\mathrm{F}(\mathrm{DOHC})] \leq 0$ & $\sum[\mathrm{F}($ Asya $)-\mathrm{F}(\mathrm{DOHC})] \leq 0$ \\
\hline Arcelik SSD dominates Asya! & Arcelik SSD dominates DOHOL! & No domination \\
\hline
\end{tabular}

\section{VERI VE YÖNTEM}

\subsection{Veri}

Bu çalışmada, uygulamalı örnek olarak, BIST-100 endeksinden belirli kurallara göre seçilen hisse senetleri seçilmiştir. Bu hisse senetleri SSD testi ile birbiriyle karşılaştırılmıştır. Kurallar, uygulama sırası ve yapulan işlemler aşağıdaki gibidir:

i) 2014 Ocak ayı itibariyle [Borç/Özsermaye] Oranı \%0 -\%50 olan BIST-100 arasındaki firmalar belirlenmiştir. BIST yalnızca firma seçmek amacıyla bir gösterge aracı gibi yani bir menü gibi kullanılmıştır. Firmaların BIST-100 içindeki ağırlıkları bu çalışmada önemli değildir. Borç oranı \%50'den fazla ve negatif orana sahip hisselerin seçilmesinin sebebi, borç oranı yüksek olan firmaların hisse senetlerindeki performansın, borç oranı düşük olan firmaların hisse senetlerindeki performansa göre daha düşük olmasıdır (Hatfield, Cheng, Davidson, 1994).

ii) Kalkınma ve Sinai Bankacılık (Yatırım Bankacılığı) dışındaki diğer bankacılık sektörleri de uygulama dışında bırakıımıştır. BIST-100 Endeksi'ndeki toplam 34 firma bu kurala uygun olarak tespit edilmiştir.

iii) BIST-100 Endeks'inden seçilen bu 34 firmanın, 2014 yılı içindeki günlük hisse senedi yüzdelik değişim değerleri alınmış (Kaynak : Thomson Reuters), bu yüzdelik değerler birer olasılık listesi olarak kabul edilmiş ve veri seti; hisselerin, bu olasılık listesindeki değerlere ne kadar dahil olduğu tespit edilerek oluşturulmuştur. Ardından hisseler birbiri ile SSD yöntemi ile karşılaştırılmıştır.

iv) SSD Testine göre en az 1 hisse senedine baskın gelen ve hiçbir hisse tarafından domine edilmeyen hisse senetlerinden 2015 yılı Ocak ayı itibarıyla eşit ağırlıklarla portföy oluşturulmuş ve 2015 Kasım ayı sonu itibarıyla bu portföyün performansı BIST-100 Endeksinin performası ile karşılaştırılmıştır.

v) SSD Testine göre en az 1 hisse senedine baskın gelen ve en az 1 hisse tarafından domine edilen hisse senetlerinden 2015 yılı Ocak ayı itibarıyla eşit ağırlıklarla ikinci bir portföy oluşturulmuş ve 2015 Kasım ayı sonu itibarıyla bu portföyün performansı BIST-100 Endeksinin performası ile karşılaştırılmıştır. 
Tablo 1: Belirlenen Kurala Uyan BIST-100 Endeksi'nden Seçilen 34 Şirketin B/ÖS Oranı

\begin{tabular}{|l|l|l|}
\hline Firma & Kod & Ratio \\
\hline Alarko Holding AS & ALARK.IS & 0,21 \\
\hline Albaraka Turk Katilim Bankasi AS & ALBRK.IS & 0,25 \\
\hline Anadolu Cam Sanayii AS & ANACM.IS & 0,47 \\
\hline Anadolu Efes Biracilik ve Malt Sanayii AS & AEFES.IS & 0,37 \\
\hline Arcelik AS & ARCLK.IS & 0,52 \\
\hline Aselsan Elektronik Sanayi ve Ticaret AS & ASELS.IS & 0,18 \\
\hline Aygaz AS & AYGAZ.IS & 0,13 \\
\hline Coca-Cola Icecek AS & CCOLA.IS & 0,47 \\
\hline Dogan Sirketler Grubu Holding AS & DOHOL.IS & 0,43 \\
\hline Dogus Otomotiv Servis ve Ticaret AS & DOAS.IS & 0,47 \\
\hline Eczacibasi Yatirim Holding Ortakligi AS & ECZYT.IS & 0,00 \\
\hline EIS Eczacibasi IIac Sinai ve FinansaI Yatirimlar Sanayi ve Ticare & ECILC.IS & 0,05 \\
\hline Emlak Konut Gayrimenkul Yatirim Ortakligi AS & EKGYO.IS & 0,06 \\
\hline Eregli Demir ve Celik Fabrikalari TAS & EREGL.IS & 0,25 \\
\hline Ford Otomotiv Sanayi AS & FROTO.IS & 0,46 \\
\hline Is Gayrimenkul Yatirim Ortakligi AS & ISGYO.IS & 0,17 \\
\hline Kardemir Karabuk Demir Celik Sanayi ve Ticaret AS & KRDMD.IS & 0,44 \\
\hline Koza Altin Isletmeleri AS & KOZAL.IS & 0,23 \\
\hline Koza Anadolu Metal Madencilik Isletmeleri AS & KOZAA.IS & 0,04 \\
\hline Petkim Petrokimya Holding AS & PETKM.IS & 0,25 \\
\hline Saf Gayrimenkul Yatirim Ortakligi AS & SAFGY.IS & 0,32 \\
\hline Soda Sanayii AS & SODA.IS & 0,16 \\
\hline TAV Havalimanlari Holding AS & TAVHL.IS & 0,48 \\
\hline Tekfen Holding AS & TKFEN.IS & 0,36 \\
\hline Tofas Turk Otomobil Fabrikasi AS & TOASO.IS & 0,42 \\
\hline Torunlar Gayrimenkul Yatirim Ortakligi AS & TRGY.IS & 0,40 \\
\hline Trakya Cam Sanayii AS & TRKCM.IS & 0,35 \\
\hline Turk Hava Yollari AO & THYAO.IS & 0,49 \\
\hline Turk Telekomunikasyon AS & TTKOM.IS & 0,34 \\
\hline Turkiye Petrol Rafinerileri AS & TUPRS.IS & 0,43 \\
\hline Turkiye Sinai Kalkinma Bankasi AS & TSKB.IS & 0,47 \\
\hline Turkiye Sise ve Cam Fabrikalari AS & SISE.IS & 0,40 \\
\hline Vestel Elektronik Sanayi ve Ticaret AS & VESTL.IS & 0,33 \\
\hline Yazicilar Holding AS & YAZIC.IS & 0,33 \\
\hline & & \\
\hline
\end{tabular}

\subsection{SSD Testinin Uygulanması}

2014 yılındaki performanslarına göre Microsoft Excel kullanılarak 34 firmanın SSD testi yani ikinci derece baskınlık testi yapılmıştır. SSD sonuçları aşağıdadır. Satır hizasından kontrol edildiğinde; 1,2 ve 3 nolu hücreler aşağıdaki anlamlara gelmektedir. Sütun hizasından bakıldığında aşağıdaki 1 ve 2 nolu kuralın tam tersi geçerlidir. (Güran,2015) :

i) 1 nolu hücre - Domine Eden (Baskın Gelen)

ii) 2 nolu gücre Domine Edilen

iii) 3 nolu hücre SSD İlişkisi Bulunmuyor 
Tablo 2: 2014 Yılı İçerisindeki Performansı Görmek Amacıyla SSD Testi Uygulanan 34 Hisse Senedinin Birbiri ile Karşılaştırılması

\begin{tabular}{|c|c|c|c|c|c|c|c|c|c|c|c|c|c|c|c|c|c|c|c|c|c|c|c|c|c|c|c|c|c|c|c|c|}
\hline Karşılaştırmalar & 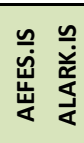 & 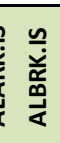 & 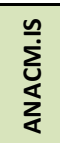 & $\begin{array}{l}\stackrel{n}{\dot{u}} \\
\frac{\ddot{z}}{\alpha}\end{array}$ & $\frac{n}{\breve{u n}}$ & $\begin{array}{l}n \\
N \\
\mathbb{N} \\
\frac{n}{<}\end{array}$ & 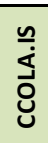 & $\frac{n}{\text { ñ }}$ & $\begin{array}{l}\text { ํㅗㄹ } \\
\text { 옴 } \\
\text { 옴 }\end{array}$ & uㅗㄹ & & $\begin{array}{l}n \\
\frac{0}{0} \\
\frac{1}{4}\end{array}$ & 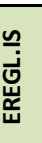 & 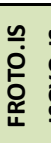 & $\begin{array}{l}\underline{\underline{n}} \\
\vdots \\
\underline{J} \\
\underline{n}\end{array}$ & $\begin{array}{l}\underline{n} \\
\dot{x} \\
\mathbf{N} \\
\underline{0}\end{array}$ & $\begin{array}{l}\simeq \\
\vec{J} \\
\underline{\underline{N}} \\
\underline{0}\end{array}$ & 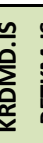 & $\stackrel{n}{n}$ & $\frac{n}{\grave{c}}$ & $\underline{\underline{u}}$ & 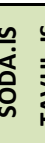 & 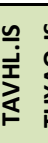 & & $\underline{n}$ & 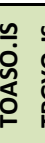 & 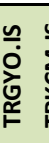 & 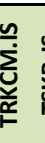 & $\stackrel{\cong}{\stackrel{n}{\dot{m}}}$ & 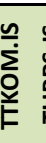 & & 气 \\
\hline AEFES.IS & 3 & 2 & 2 & 2 & 2 & 2 & 3 & 3 & 3 & 2 & 2 & 2 & 2 & 2 & 2 & 1 & 1 & 3 & 2 & 3 & 2 & 2 & 2 & 2 & 2 & 3 & 3 & 2 & 2 & 2 & 2 & 3 \\
\hline ALARK.IS & & 2 & 3 & 3 & 3 & 3 & 3 & 3 & 3 & 2 & 2 & 3 & 3 & 3 & 2 & 1 & 1 & 3 & 2 & 3 & 3 & 2 & 3 & 3 & 3 & 3 & 3 & 3 & 2 & 2 & 3 & 3 \\
\hline ALBRK.IS & & & 3 & 3 & 3 & 3 & 1 & 3 & 1 & 3 & 2 & 3 & 3 & 3 & 3 & 1 & 1 & 3 & 3 & 1 & 3 & 3 & 3 & 3 & 3 & 3 & 3 & 3 & 3 & 3 & 3 & 3 \\
\hline ANACM.IS & & & & 3 & 2 & 3 & 3 & 3 & 3 & 3 & 2 & 3 & 3 & 3 & 3 & 1 & 1 & 3 & 3 & 1 & 3 & 2 & 3 & 3 & 3 & 3 & 3 & 3 & 3 & 3 & 3 & 3 \\
\hline ARCLK.IS & & & & & 2 & 3 & 3 & 3 & 1 & 3 & 3 & 3 & 3 & 3 & 3 & 1 & 1 & 3 & 3 & 1 & 3 & 2 & 3 & 3 & 3 & 3 & 3 & 3 & 3 & 3 & 3 & 3 \\
\hline ASELS.IS & & & & & & 3 & 1 & 3 & 1 & 3 & 3 & 3 & 3 & 3 & 3 & 1 & 1 & 3 & 31 & 1 & 3 & 3 & 1 & 3 & 3 & 1 & 1 & 3 & 3 & 3 & 1 & 3 \\
\hline AYGAZ.IS & & & & & & & 3 & 3 & 3 & 3 & 3 & 3 & 3 & 3 & 3 & 1 & 1 & 3 & 3 & 1 & 3 & 3 & 3 & 3 & 3 & 3 & 3 & 3 & 3 & 3 & 3 & 3 \\
\hline CCOLA.IS & & & & & & & & 3 & 3 & 2 & 2 & 3 & 3 & 2 & 2 & 1 & 1 & 3 & 2 & 3 & 3 & 2 & 3 & 3 & 3 & 3 & 3 & 3 & 2 & 2 & 3 & 3 \\
\hline DOAS.IS & & & & & & & & & 3 & 3 & 3 & 3 & 3 & 3 & 3 & 3 & 1 & 3 & 3 & 3 & 3 & 3 & 3 & 3 & 3 & 3 & 3 & 3 & 3 & 3 & 3 & 3 \\
\hline DOHOL.IS & & & & & & & & & & 2 & 2 & 3 & 3 & 2 & 2 & 1 & 1 & 3 & 2 & 3 & 3 & 2 & 3 & 3 & 3 & 3 & 3 & 3 & 2 & 2 & 3 & 3 \\
\hline ECILC.IS & & & & & & & & & & & 3 & 3 & 3 & 3 & 3 & 1 & 1 & 3 & 3 & 1 & 3 & 3 & 3 & 3 & 3 & 3 & 3 & 3 & 3 & 3 & 3 & 3 \\
\hline ECZYT.IS & & & & & & & & & & & & 3 & 3 & 3 & 3 & 1 & 1 & 3 & 3 & 1 & 3 & 3 & 3 & 3 & 1 & 3 & 3 & 3 & 3 & 3 & 3 & 3 \\
\hline EKGYO.IS & & & & & & & & & & & & & 3 & 3 & 3 & 1 & 1 & 3 & 3 & 1 & 3 & 3 & 3 & 3 & 1 & 1 & 1 & 3 & 3 & 3 & 3 & 3 \\
\hline EREGL.IS & & & & & & & & & & & & & & 3 & 3 & 1 & 1 & 3 & 3 & 1 & 1 & 3 & 3 & 3 & 3 & 3 & 3 & 3 & 3 & 3 & 3 & 3 \\
\hline FROTO.IS & & & & & & & & & & & & & & & 3 & 1 & 1 & 3 & 3 & 1 & 3 & 2 & 1 & 3 & 1 & 1 & 1 & 3 & 3 & 3 & 3 & 3 \\
\hline ISGYO.IS & & & & & & & & & & & & & & & & 1 & 1 & 3 & 3 & 1 & 3 & 3 & 3 & 3 & 3 & 3 & 3 & 3 & 3 & 3 & 3 & 3 \\
\hline KOZAA.IS & & & & & & & & & & & & & & & & & 3 & 2 & 2 & 3 & 2 & 2 & 2 & 2 & 2 & 2 & 2 & 2 & 2 & 2 & 2 & 3 \\
\hline KOZAL.IS & & & & & & & & & & & & & & & & & & 2 & 2 & 2 & 2 & 2 & 2 & 2 & 2 & 2 & 2 & 2 & 2 & 2 & 2 & 3 \\
\hline KRDMD.IS & & & & & & & & & & & & & & & & & & & 3 & 1 & 3 & 3 & 3 & 3 & 3 & 1 & 3 & 3 & 3 & 3 & 3 & 3 \\
\hline PETKM.IS & & & & & & & & & & & & & & & & & & & & 1 & 3 & 2 & 1 & 3 & 3 & 1 & 1 & 3 & 3 & 3 & 3 & 3 \\
\hline SAFGY.IS & & & & & & & & & & & & & & & & & & & & & 2 & 2 & 2 & 2 & 2 & 2 & 2 & 2 & 2 & 2 & 2 & 3 \\
\hline SISE.IS & & & & & & & & & & & & & & & & & & & & & & 2 & 3 & 3 & 3 & 3 & 3 & 3 & 3 & 3 & 3 & 3 \\
\hline SODA.IS & & & & & & & & & & & & & & & & & & & & & & & 1 & 1 & 1 & 1 & 1 & 1 & 3 & 1 & 1 & 3 \\
\hline TAVHL.IS & & & & & & & & & & & & & & & & & & & & & & & & 3 & 3 & 3 & 3 & 3 & 2 & 3 & 3 & 3 \\
\hline THYAO.IS & & & & & & & & & & & & & & & & & & & & & & & & & 3 & 1 & 3 & 3 & 3 & 3 & 3 & 3 \\
\hline TKFEN.IS & & & & & & & & & & & & & & & & & & & & & & & & & & 3 & 3 & 3 & 2 & 2 & 3 & 3 \\
\hline TOASO.IS & & & & & & & & & & & & & & & & & & & & & & & & & & & 3 & 3 & 2 & 3 & 3 & 3 \\
\hline TRGYO.IS & & & & & & & & & & & & & & & & & & & & & & & & & & & & 3 & 2 & 3 & 3 & 3 \\
\hline TRKCM.IS & & & & & & & & & & & & & & & & & & & & & & & & & & & & & 3 & 3 & 3 & 3 \\
\hline TSKB.IS & & & & & & & & & & & & & & & & & & & & & & & & & & & & & & 3 & 3 & 3 \\
\hline Tтком.IS & & & & & & & & & & & & & & & & & & & & & & & & & & & & & & & 3 & 3 \\
\hline TUPRS.IS & & & & & & & & & & & & & & & & & & & & & & & & & & & & & & & & 3 \\
\hline VESTL.IS & & & & & & & & & & & & & & & & & & & & & & & & & & & & & & & & \\
\hline ZIC.IS & & & & & & & & & & & & & & & & & & & & & & & & & & & & & & & & \\
\hline
\end{tabular}

\section{BULGULAR VE TARTIŞMA}

\subsection{Test Sonuçları}

2014 yılı içindeki günlük performansları değerlendirilerek yapılan SSD testindeki hisse senedi bazlı baskınlık sayısını da gösteren değerler Tablo 3'de belirtilmiştir.

Tablo 3: SSD Testi Sonucuna Göre 2014 Yılı İçin Firmaların Bireysel Performansları

\begin{tabular}{|c|c|c|c|c|c|c|c|c|c|c|c|}
\hline Şirket H. & $\begin{array}{l}\text { SSD Iilişkisi } \\
\text { Yok }\end{array}$ & $\begin{array}{c}\text { Domine } \\
\text { Eden }\end{array}$ & $\begin{array}{c}\text { Domine } \\
\text { Edilen }\end{array}$ & Şirket H. & $\begin{array}{c}\text { SSD ilişskisi } \\
\text { Yok }\end{array}$ & $\begin{array}{c}\text { Domine } \\
\text { Eden }\end{array}$ & $\begin{array}{c}\text { Domine } \\
\text { Edilen }\end{array}$ & Şirket H. & $\begin{array}{l}\text { SSD Iilişkisi } \\
\text { Yok }\end{array}$ & $\begin{array}{c}\text { Domine } \\
\text { Eden }\end{array}$ & $\begin{array}{c}\text { Domine } \\
\text { Edilen }\end{array}$ \\
\hline AEFES.IS & 9 & 2 & 22 & EKGYO.IS & 26 & 7 & 0 & THYAO.IS & 27 & 5 & 1 \\
\hline ALARK.IS & 23 & 2 & 8 & EREGL.IS & 28 & 5 & 0 & TKFEN.IS & 23 & 4 & 6 \\
\hline ALBRK.IS & 25 & 7 & 1 & FROTO.IS & 22 & 10 & 1 & TOASO.IS & 22 & 3 & 8 \\
\hline ANACM.IS & 26 & 4 & 3 & ISGYO.IS & 25 & 8 & 0 & TRGYO.IS & 24 & 3 & 6 \\
\hline ARCLK.IS & 26 & 5 & 2 & KOZA.A.IS & 4 & 0 & 29 & TRKCM.IS & 28 & 4 & 1 \\
\hline ASELS.IS & 21 & 12 & 0 & KOZAL.IS & 2 & 0 & 31 & TSKB.IS & 22 & 11 & 0 \\
\hline AYGAZ.IS & 29 & 4 & 0 & KRDMD.IS & 29 & 4 & 0 & TTKом.IS & 24 & 8 & 1 \\
\hline CCOLA.IS & 20 & 2 & 11 & PETKM.IS & 22 & 10 & 1 & TUPRS.IS & 27 & 4 & 2 \\
\hline DOAS.IS & 32 & 1 & 0 & SAFGY.IS & 7 & 1 & 25 & VESTL.IS & 33 & 0 & 0 \\
\hline DOHOL.IS & 20 & 2 & 11 & SISE.IS & 27 & 4 & 2 & YAZIC.IS & 26 & 5 & 2 \\
\hline ECILC.IS & 26 & 7 & 0 & SODA.IS & 13 & 20 & 0 & & & & \\
\hline ECZYT.IS & 22 & 11 & 0 & TAVHL.IS & 24 & 4 & 5 & & & & \\
\hline
\end{tabular}

SSD testi sonuçlarına göre "en az 1 hisseyi domine eden ve hiçbir hisse tarafından domine edilmeyen" toplam 11 dominant hisse senedi bulunmuştur. 
En az 1 hisse senedi tarafından domine edilen ve hiç domine edemeyen 2 adet firmanın hisse senedi olmuştur. Hem en az 1 bir firmayı domine eden ve en az 1 hisse senedi tarafından domine edilen 20 firma bulunmuştur.

Hiçbir hisse senedi tarafından domine edilmeyen ve hiçbir hisseyi domine etmeyen yani hiçbir hisse senedi ile SSD ilişkisi kuramayan yalnızca bir adet hisse senedi bulunmuştur. Tablo 4 de bu firmalar belirtilmiştir.

Tablo 4: SSD Testi Sonuçlarına Göre Firma Dağılımları

\begin{tabular}{|c|c|c|c|c|}
\hline $\begin{array}{l}\text { En az } 1 \text { hisseyi domine } \\
\text { edenler ve hiç domine } \\
\text { edilmeyenler }\end{array}$ & $\begin{array}{l}\text { En az } 1 \text { hisse tarafından } \\
\text { domine edilenler ve hiç } \\
\text { domine edemeyenler }\end{array}$ & \multicolumn{2}{|c|}{$\begin{array}{l}\text { Hem domine edip hem } \\
\text { de domine edilenler }\end{array}$} & $\begin{array}{l}\text { Hiçbir hisse tarafından } \\
\text { domine edilmeyen ve } \\
\text { hiçbir hisseyi domine } \\
\text { etmeyen }\end{array}$ \\
\hline $11 \mathrm{ADET}$ & 2 ADET & \multicolumn{2}{|c|}{ 20 ADET } & $1 \mathrm{ADET}$ \\
\hline ASELS.IS & KOZAA.IS & AEFES.IS & TAVHL.IS & VESTL.IS \\
\hline AYGAZ.IS & KOZAL.IS & ALARK.IS & THYAO.IS & \\
\hline DOAS.IS & & ALBRK.IS & TKFEN.IS & \\
\hline ECILC.IS & & ANACM.IS & TOASO.IS & \\
\hline ECZYT.IS & & ARCLK.IS & TRGYO.IS & \\
\hline EKGYO.IS & & CCOLA.IS & TRKCM.IS & \\
\hline EREGL.IS & & DOHOL.IS & TTKOM.IS & \\
\hline ISGYO.IS & & FROTO.IS & TUPRS.IS & \\
\hline KRDMD.IS & & PETKM.IS & YAZIC.IS & \\
\hline SODA.IS & & SAFGY.IS & & \\
\hline TSKB.IS & & SISE.IS & & \\
\hline
\end{tabular}

\subsection{BIST-100 Endeksi ile Baskın Hisse Senetleri Portföyünün Karşılaştırılması}

2014 yılı sonunda SSD testinden tespit edilen 11 adet firmadan bir portföy oluşturulmuştur. Bu firmaların hisse senetlerinden eşit tutarlarda alınmaktadır. Hisse senedi sayı olarak eşitlikten ziyade, tutar olarak eşit dağılıma sahiptir. Bu portföy ile BIST-100 Endeksi 29.11.2015 (Kasım, 2015) tarihindeki durumuna göre karşılaştırılmıştır. BIST-100 Endeksi'nin 2015 Ocak-Kasım performansı negatif bir performans yani \% -15 gösterirken, baskın gelen hisselerle oluşturulan portföyün getirisi hem pozitif hem de enflasyon değerine yakın bir değer olarak \% 12 getiri sağlamıştır. Tablo 5'de hem baskın gelen hisselerin, hem o hisselerden oluşturulan portföyün hem de Endeksin getirisi gösterilmiştir. Bu durum $\mathrm{H}_{0}$ hipotezini doğrular. Yani , \%0-50 toplam borç/özsermaye oranına sahip olan BIST100 içinden seçilen firmaların hisse senetlerine, 2.dereceden stokastik baskınlık testi uygulamasıyla oluşturulan bir portföyün belirli bir dönem sonrasındaki getirisi; aynı döneme ait olan BIST100'ün kendi getirisinden fazladır.

Tablo 5: Portföy-1 ve BIST-100 Endeksi Karşılaştırma Tablosu

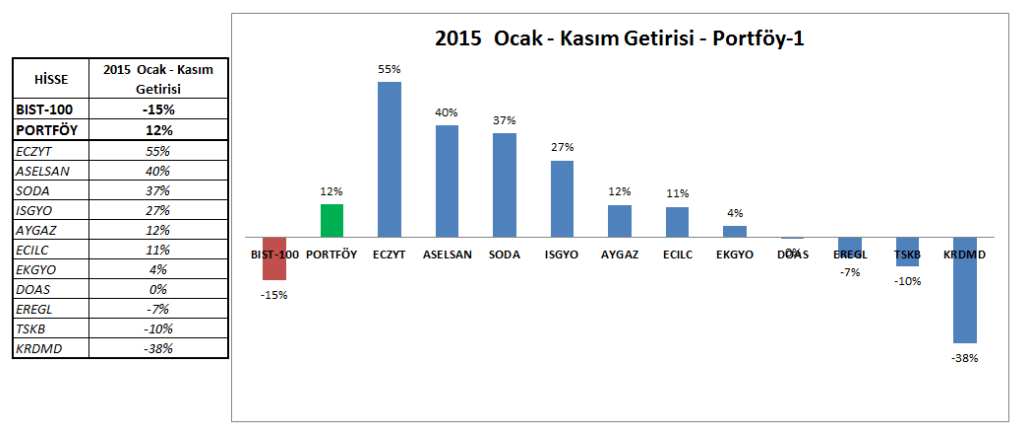




\subsection{BIST-100 Endeksi ile Farklı Baskınlık Oranlarına Sahip Hisse Senetleri ile Oluşturulan Portföyün Karşılaştırılması}

2014 yılı sonunda SSD testinden tespit edilen "hem en az 1 hisse senedine karşı baskın gelen ve en az 1 hisse senedine karşı domine edilen" 20 adet firmanın hisse senetlerinden bir portföy oluşturulmuştur. Bu firmaların hisse senetlerinden eşit tutarlarda alınmaktadır.

Hisse senedi sayı olarak eşitlikten ziyade, tutar olarak eşit dağılıma sahiptir. Bu portföy ile BIST-100 Endeksi 29.11.2015 (Kasım, 2015) tarihindeki durumuna göre karşılaştırılmıştır.

BIST-100 Endeksi'nin 2015 Ocak-Kasım performansı negatif bir performans yani \% -15 göstermiştir. 20 adet firmasan oluşturulan portföy-2 olarak adlandırılan portföy de negatif performans göstermiştir yani \% $-8^{\prime}$ lik bir değer kaybı mevcuttur..

Tablo 6'da Portföy-2, Portföy-2'yi oluşturan hisselerin performansı ve Endeksin getiri performansı gösterilmiştir.

Tablo 6: Portföy-2 ve BIST-100 Endeksi Karşılaştırma Tablosu

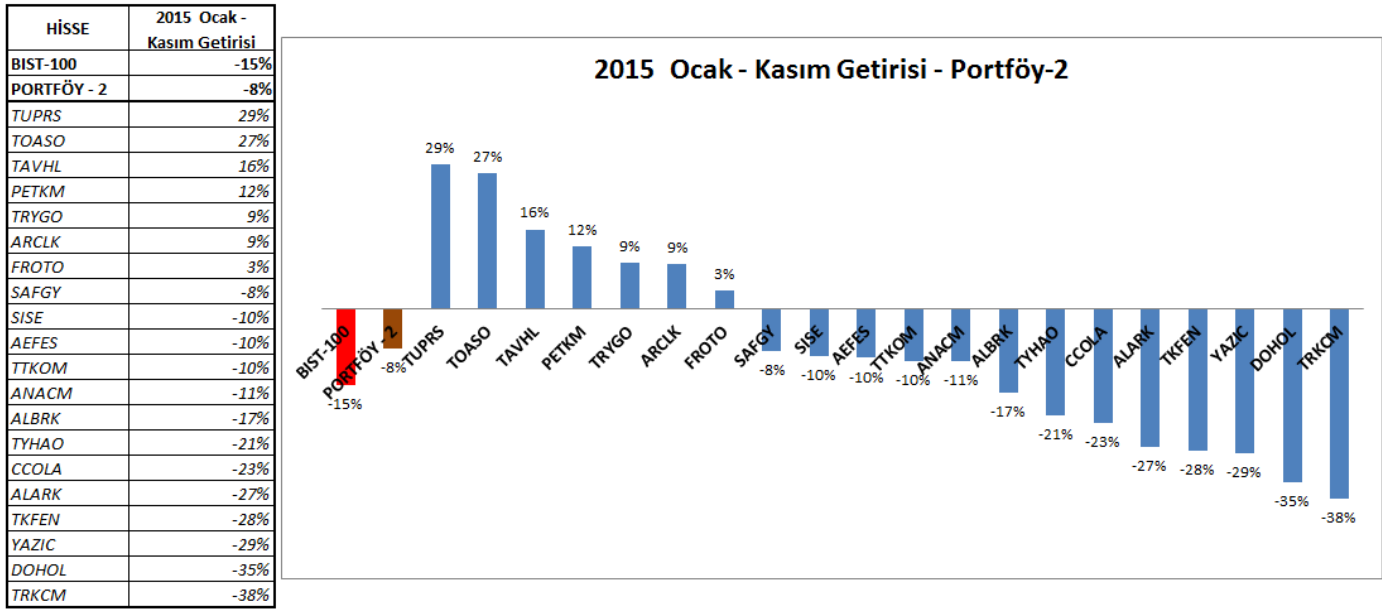

\subsection{Portföylere Dahil Olmayan Hisselerin Performansı}

Hiçbir hisse senedine karşı baskın gelemeyen (KOZAA, KOZAL) ve hiçbir hisse senedi ile SSD ilişkisi olmayan hisselerin (VESTL) BIST-100 ile karşılaştırılması Tablo-7' de gösterilmiştir. Baskın gelemeyen firmalar endekse göre daha kötü performans göstermişlerdir. Hiçbir firma ile SSD ilişkisi olmayan VESTL hissesi ise endekse yakın bir değer ile negatif performans göstermiştir.

Tablo 7: BIST-100 Endeksi ve Diğer Hisseler Karşılaştırma Tablosu

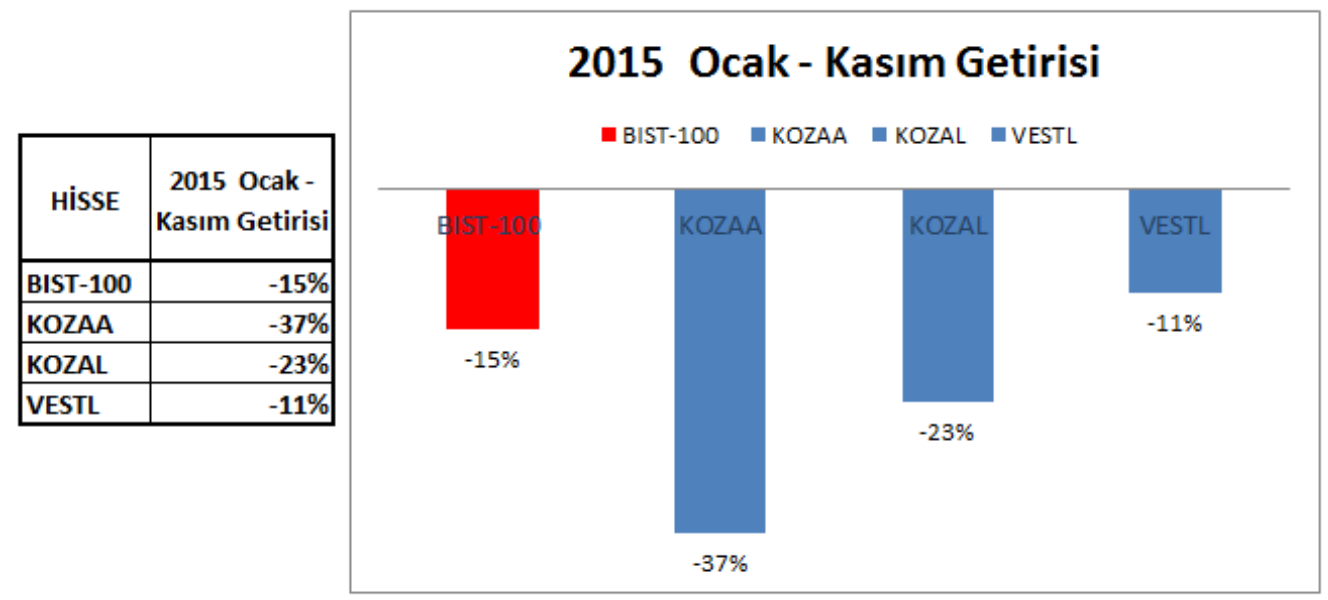




\section{SONUÇ}

Varyans maksimizasyonu yönteminin zayıf yönlerini bertaraf eden stokastik baskınlık yöntemi ile oluşturulan portföy, pozitif getiri sağlamıştır. Bu pozitif getiri BIST-100 endeksinin negatif getiri ile kapandığı yılda elde edilmiştir. SSD testi ile tespit edilen dominant firmaların hisse senetleri endeksten daha yüksek getiri elde etmiştir. Ancak, BIST-100 endeksindeki 100 firmayı 34'e indiren [Borç/Özsermaye] oranı değeri de bu pozitif etkinin yaratılmasına katkı sağlamıştır. Şöyle ki; eğer 34 firma değil de 100 firma üzerinde SSD testi uygulansaydı, bu test sonucundan çıkacak olan baskın hisselerden oluşturulan bir portföyün değeri \% -15 (BIST-100) ile \% +12 (Portföy-1) arasında olacaktı. Bu sebeple; [Borç/Özsermaye] oranı düşük olan firmaların daha iyi getiri elde ettiği sonucuna varılabilir. Aksine piyasada geçen genel kabul, borçlanma maliyetinin az olduğu ve tercih edilebilir olduğu yönündedir.

Negatif seyreden endeks pazarlarında, Portföy-2 olarak SSD testine göre oluşturulan kategori de negatif getiri sağlamıştır. Yalnızca baskın gelen hisselerle portföy oluşturmak bu sonuca göre daha makuldur.

Bu durumda borç oranı daha az olan firmaların daha baskın geldiği sonucuna varılabilir, ancak bu alanda daha ayrıntılı analizler yapılmalıdır. Borçlanma maliyetinin daha az olmasına rağmen borcu az olan firmaların hisse senetlerinin daha iyi performans göstermesi bu çalışmada soru işareti bırakan noktadır. Bu durum gösterilen olağanüstü parasal genişleme dönemi çıkış kısmına (Türkiye ihracatçılar Meclisi,2014) yani 2009 yılına işaret etmektedir. Bu çalışmada incelenen dönem, genişleme döneminden çıkışa denk düşmektedir. Her ne kadar parasal genişleme dönemi 2014 yılı sonuna doğru azalsa da, hisse senetleri değerlerindeki anormal artışlar, dönemin henüz tam anlamıyla kapanmadığından, piyasada para arzının bulunması suretiyle, hisse senedi alış satış işleminin fazlaca olmasından dolayı olabilir. İkinci bir tahmin ise, davranışsal finans ile ilgilisi olduğu yönündedir. BIST'te hisse senetlerinde işlem yapan yerli yatırımcılar, borcu az olan firmalara, borcu fazla olan firmalara nazaran daha fazla güvenebilirler, bu güven duygusu borcu az olan firmalara talebi arttırmış olup, parasal genişleme dönemi ile birlikte hisse senetlerinin değerlerinde sebep olmuş olabilir.

\section{KAYNAKLAR}

Alaoui, Dewandaru, Rosly ve Masih. 2014, "Linkages and co-movement between international stock market returns: Case of Dow Jones Islamic Dubai Financial Market index." Journal of International Financial Markets, Institutions \& Money.

Booth L., Aivazian V., Kunt A., Maksimovic V., 2001. "Capital Structure in Developing Countries." The Journal of Finance, Vol 56, No.1 - 87130

Baxter, N. 1967, "Leverage, Risk of Ruin and the Cost of Capital", Journal of Finance , pp.3956-403

Donaldson G. 1963, “Financial Goals: Management vs Stockholders”, Harvard Business Review 41, 116-129

Erdamar H., Ersen H., Ekinci C., Taş O., Şimsek D. 2015, “Capital Structure of Dow Jones Islamic Index Firms”

Güran B., Taş O. 2014, "Making Second Order Stochastic Dominance inefficient Mean Variance Portfolio efficient: Application in Turkish BIST-30 Index.", iktisat işletme ve Finans Dergisi, 95-126.

Hatfield G., Louis C., Davidson W., 1994. The Determination of Optimal Capital Structure: The Effect of Firm and Industry Debt Ratios on Market Value. Journal of Financial and Strategic Decision, 3-13.

Jensen, M.C., Meckling, W.H., 1976. "Theory of the firm: managerial behavior, agency costs, and ownership structure.", Journal of Financial Economics, 3, 305-360.

Masulis W., D'Angelo H. 1980, “Optimal Capital Structure Under Corporate and Personal Taxation”, Journal of Financial Economics, Vol. 8 , No. 1, pp. 3-27, 1980

Masulis W. 1983, "The Impact of Capital Structure Change on Firm Value", The Journal of Finance, Volume 38 Issue 1 Pages $107-126$

Mazouz, Mohamed, Saadouni. 2016." Stock return comovement around the Dow Jones Islamic Market World Index revisions". Journal of Economic Behaviour \& Organization.

Modigliani F., Miller H. 1958, "The Cost of Capital, Corporation Finance and the Theory of Investment", The American Economic Review, Vol. 48, No. 3 pp. 261-297

Stiglitz J. 1972 ," Some Aspects of the Pure Theory of Corporate Finance: Bankruptcies and Take-Overs", Bell Journal of Economics.

Türkiye İhracatçılar Meclisi, Olağanüstü Parasal Genişleme Dönemi Sunumu, Ankara 2014 